\title{
INFLUÊNCIA DO RELEVO NOS INCÊNDIOS EM VEGETAÇÃO EM JUIZ DE FORA (MG)
}

\author{
FILLIPE TAMIOZZO PEREIRA TORRES ${ }^{1}$ \\ GUIDO ASSUNÇÃO RIBEIRO \\ SEBAstião VEnÂNCIO MARTINS ${ }^{3}$ \\ GUMERCINDO SOUZA LIMA ${ }^{4}$ \\ Universidade Federal de Viçosa
}

Resumo: Os incêndios em vegetação podem provocar prejuízos irreversíveis ao ambiente, como os danos à fauna e à flora, às pessoas, além de consequências econômicas consideráveis. Para estabelecer políticas de controle e prevenção, faz-se necessário conhecer o perfil dos incêndios. Com esses dados pode-se planejar o controle de modo mais eficiente, diminuindo gastos, tempo e riscos em seu combate. Utilizando o endereço das ocorrências na cidade de Juiz de Fora (MG), foi determinada a orientação da vertente, a forma da vertente e a declividade do terreno, a fim de se analisar a influência do relevo sobre o número de eventos. Vertentes com exposição norte, com maior declividade e formas que facilitam o escoamento da água apresentam maior número de casos. A influência do relevo é confirmada também pela relação entre a direção do vento e as ocorrências. Vertentes que recebem diretamente os ventos diários predominantes apresentam maior probabilidade de ocorrências de incêndios.

Palavras-chave: Geomorfologia; Fogo; Susceptibilidade.

\footnotetext{
${ }^{1}$ Professor adjunto do Departamento de Engenharia Florestal da Universidade Federal de Viçosa. Contato: torresftp@yahoo.com.br.

${ }^{2}$ Professor, DSc. em Eng. Florestal - UFV - DEF - Viçosa - MG. Contato: gribeiro@ufv.br (in memoriam).

3 Professor, DSc. em Ciências Biológicas UFV - DEF - Viçosa - MG. Contato: venancio@ufv.br.

${ }^{4}$ Professor, DSc. em Ciência Florestal - UFV - DEF - Viçosa - MG. Contato: gslima@ufv.br.
} 


\section{INFLUENCE OF RELIEF ON VEGETATION FIRES IN JUIZ DE FORA (MG)}

Abstract: Forest fires can cause irreversible damages to the environment, such as damage to fauna and flora, people, and considerable economic consequences. To establish policies for the control and prevention, it is necessary to know the profile of the fires. With these data, one can control planning more efficiently, reducing costs, time and risks in their control. Using the location of occurrences in the city of Juiz de Fora (MG), we determined the orientation of the slope, the form the slope and the slope's declivity. Slopes with northern exposure, with steeperslopes and forms that facilitate the flow of water exhibit a higher number of events. This influence of relief is also confirmed by the relationship between wind direction and occurrences. Aspects that directly receive the daily prevailing winds have a higher probability of fire occurrences.

Keywords: Geomorphology; Fire; Susceptibility.

\section{Introdução}

Os incêndios em vegetação são responsáveis diretos não apenas por danos ambientais, mas também por prejuízos econômicos e sociais cujas dimensões muitas vezes atingem níveis incalculáveis (VOSGERAU et al., 2006).

Existem dois tipos de fatores determinantes do grau de perigo de incêndio: os fatores constantes, representados pelo tipo de material combustível, o qual envolve os diferentes tipos de vegetação e o relevo; e os fatores variáveis, representados pelas condições atmosféricas (TORRES et al., 2011). Ainda para os autores, dentre os fatores constantes, destacam-se a topografia e o uso e ocupação do solo.

A topografia, segundo Batista (2000), influi diretamente no clima e determina o tipo de combustível de uma região. Considerando que o comportamento do fogo é em grande medida o resultado do clima e do combustível disponíveis, pode-se dizer, dessa forma, que a topografia influi indiretamente no comportamento do fogo e diretamente pela proximidade das chamas quanto maior a inclinação, tornando as informações sobre o relevo fundamentais no estabelecimento de planos de prevenção e controle.

No Brasil existe uma carência de planos de prevenção e controle efetivos. Planos estes que só podem ser organizados e colocados em prática mediante avaliação de informações que relatem precisamente as características das ocorrências dos incêndios (VOSGERAU et al., 2006).

De acordo com Santos, Soares e Batista (2006), para preservar o meio ambiente dos efeitos nocivos dos incêndios são essenciais políticas protecionistas adequadas às características de cada região. Para estabelecer estas políticas de controle e prevenção, faz-se necessário conhecer o momento 
e os porquês das ocorrências dos eventos, ou seja, o perfil dos incêndios em vegetação. As estatísticas de ocorrência são as principais ferramentas para se traçar seu perfil. Com esses dados, pode-se planejar o controle de modo mais eficiente; sem essas informações, pode-se subestimar ou superestimar os gastos referentes à proteção do meio ambiente, colocando em risco a sobrevivência das florestas e dos combatentes.

Ainda para os autores, para priorizar as regiões de maior risco por meio de programas intensivos de proteção e estruturar os serviços de combate a incêndios dentro de limites economicamente viáveis é importante saber os locais e os fatores que favorecem as ocorrências e sua propagação. Conhecendo-se os fatores que contribuem para a maior incidência do fogo, é possível concentrar esforços e recursos para combatê-lo, pois tais sistemas são relativamente caros e seria inviável mantê-los ininterruptamente em todos os locais.

Diante do exposto, o objetivo deste estudo é analisar a influência do relevo como a exposição das vertentes ao Sol, a forma das vertentes, a declividade e sua posição em relação aos ventos predominantes - sobre as ocorrências de incêndios em vegetação na cidade de Juiz de Fora (MG), a fim de traçar o perfil dos eventos e, consequentemente, fornecer ao poder público ferramentas para o melhor dimensionamento das políticas de prevenção e combate.

\section{Material e Métodos}

O município de Juiz de Fora, com uma população de 516.247 habitantes (IBGE, 2010), localiza-se no sudeste do estado de Minas Gerais, estando o centro da cidade nas coordenadas $21^{\circ} 41^{\prime} 20^{\prime}$ ' S e $43^{\circ} 20^{\prime} 40^{\prime \prime} \mathrm{W}$ (ver Figura 1).

A área distingue-se por ser montanhosa, com altitudes próximas a 1.000 metros nos pontos mais elevados e 670 a $750 \mathrm{~m}$ no fundo do vale. O Perímetro Urbano do Município insere-se totalmente no curso médio do rio Paraibuna, pertencente à bacia do rio Paraíba do Sul (PJF, 1996). 


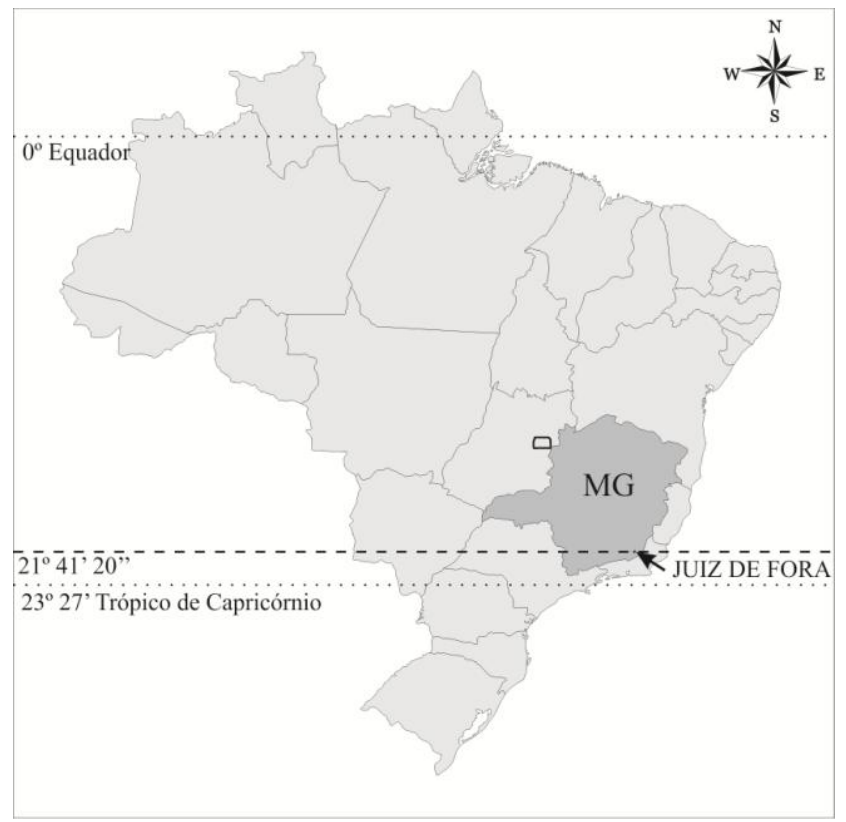

Figura 1: Localização da área de estudo.

Fonte: Torres (2008).

Os padrões de relevo mostram uma forte tendência à orientação estrutural. Suas litologias caracterizam-se por apresentarem coberturas de solos espessos e exposições rochosas, principalmente nas áreas de ocorrência das rochas Charnockíticas, ao sul do município. Em geral, as feições geomorfológicas tendem a uma convexidade das vertentes a partir do topo, aliada à formação de grande número de anfiteatros e planícies intermontanas (mar de morros). O núcleo central da cidade, aproveitando-se desta condição natural, alojou-se na seção alargada do vale do rio Paraibuna, estrangulada por uma barra resistente, a jusante (PJF, 1996).

Os dados de ocorrências de incêndios em vegetação foram obtidos no $4^{\circ}$ Batalhão de Bombeiros Militares (4 $\left.4^{\circ} \mathrm{BBM}\right)$. Nos registros estão disponíveis a natureza, a data, hora e endereço, entre o período de 01/01/2002 a 31/12/2011, no qual foram registradas 3.754 ocorrências dentro da área urbana do município.

A partir de visitas a campo, todos os locais de ocorrências foram georreferenciados e suas características tabuladas. As exposições das vertentes foram agrupadas em Norte $\left(315^{\circ}\right.$ a $\left.45^{\circ}\right)$, Leste $\left(45^{\circ}\right.$ a $\left.135^{\circ}\right), \operatorname{Sul}\left(135^{\circ}\right.$ a $\left.225^{\circ}\right)$ e 
Oeste $\left(225^{\circ}\right.$ a $\left.315^{\circ}\right)$, com a utilização de uma bússola. As formas das vertentes, por meio de interpretação visual, foram divididas nas classes côncava, convexa e retilínea; e as declividades, com a utilização de um clinômetro tipo Abney, foram agrupadas nas classes de $0^{\circ}$ a $10^{\circ}, 10^{\circ}$ a $20^{\circ}, 20^{\circ}$ a $30^{\circ}, 30$ a $40^{\circ}$ e $>40^{\circ}$.

As direções preferenciais dos ventos foram registradas na Estação Climatológica Principal (ECP), localizada no campus da Universidade Federal de Juiz de Fora (UFJF). Os dados foram coletados às 9:00, 15:00 e 21:00 TMG. A partir das leituras dos três horários, foram determinadas as direções preferenciais para cada dia da série divididas em Norte, Nordeste, Noroeste, Oeste, Leste, Sul, Sudeste e Sudoeste.

\section{Resultados e Discussão}

A Figura 2 mostra que houve uma influência significativa da exposição das vertentes sobre as ocorrências, em que a maior parte dos incêndios ocorreu nas encostas voltadas para o Norte seguidas das voltadas para o Oeste (W), Leste (E) e a menor parte nas voltadas para o Sul (S).

Esta distribuição se deve ao fato de superfícies com orientações e inclinações diferentes receberem quantidades diferentes de radiação solar global em comparação com uma superfície plana, em uma mesma localidade e época do ano (TORRES \& MACHADO, 2011).

Ainda de acordo com os autores, o Sol culmina no zênite (representando maior ganho energético) em locais cuja latitude é igual ao valor da inclinação do eixo da Terra. Assim, nos equinócios (21 de março e 23 de setembro) o Sol culmina no zênite sobre o Equador, apresentando em todos os pontos da Terra dias e noites com a mesma duração. No solstício de verão no Hemisfério Sul e solstício de inverno no Hemisfério Norte (22 de dezembro), o Sol culmina no zênite para a latitude $-23^{\circ} 27^{\prime}$ (Sul); pelo fato desta ser a maior declinação alcançada no Hemisfério Sul, essa latitude recebe o nome de Trópico de Capricórnio. Em 21 de junho o Sol culmina no zênite para 23 $27^{\prime}$ (Norte), latitude que define a posição do Trópico de Câncer, tem-se, assim, o solstício de verão no Hemisfério Norte e o solstício de inverno no Hemisfério Sul. Nas latitudes superiores a $23^{\circ} 27^{\prime}$ o Sol não culmina zenitalmente em dia nenhum do ano. 


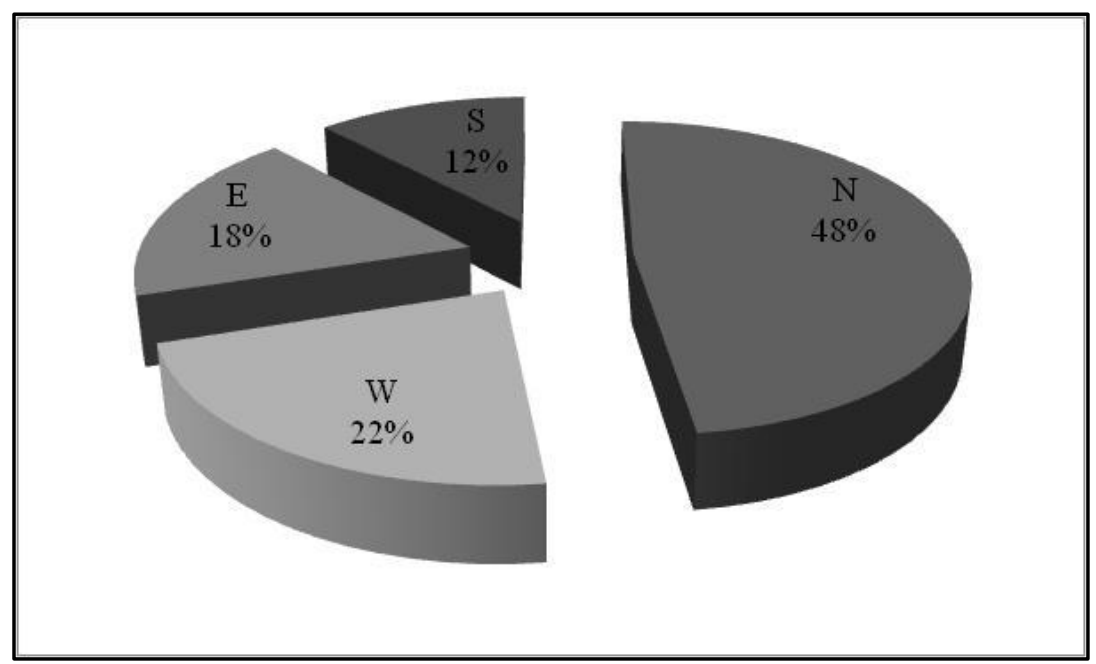

Figura 2: Ocorrências de incêndios de acordo com a exposição da vertente.

Observa-se que o Sol durante grande parte do ano culmina no zênite ao Norte do município de Juiz de Fora, localizado na latitude de $21^{\circ} 41^{\prime} 20^{\prime}$ 'S. Esse fator tende a elevar a temperatura nas vertentes de orientação Norte influenciando diretamente nas características físicas do material combustível e ocorrências de incêndios.

A diferença entre as vertentes voltadas para o Oeste e para o Leste pode ser explicada pela hora de maior concentração de ocorrências, (entre 15 e 16 horas); durante este horário a vertente voltada para o Oeste está recebendo maior quantidade de energia solar em relação à vertente voltada para o Leste, aumentando a porcentagem das ocorrências. Outro fator é o fato da vertente Oeste receber maior quantidade de energia na parte da tarde, quando a superfície terrestre e o ar já estão aquecidos e normalmente não existe neblina. Além destes, as vertentes voltadas para o Leste recebem ventos úmidos vindos do Oceano Atlântico, distante, em linha reta, cerca de $150 \mathrm{~km}$ do município.

Hugget (1995) corrobora ao destacar que, no Hemisfério Sul, encostas orientadas para o Norte recebem maior insolação que aquelas voltadas para o Sul, as quais, por sua vez, recebem maiores precipitações devido aos ventos carregados de umidade vindos do mar (SW, S e SE). Oliveira et al. (1995), em estudos conduzidos no Maciço da Tijuca, encontraram diferenças significativas para as duas vertentes no que diz respeito a parâmetros como temperatura, precipitação e umidade. Segundo tais autores, as encostas voltadas para o Sul possuem serapilheira em média $41,9 \%$ mais úmida que as voltadas para o 
Norte. Os autores afirmam, ainda, que a perda desta umidade também se dá muito mais rápido nas encostas voltadas para o Norte, pois as voltadas para o Sul retêm a umidade 1,6 vezes mais. Consequentemente, a umidade do solo se comporta da mesma maneira, apenas variando de acordo com o tipo de cobertura vegetal a que está associada.

Esta variação de umidade se reflete basicamente em função dos diferentes índices de temperatura destes dois tipos de encosta, visto que as encostas voltadas para o Norte são significativamente mais quentes, devido à maior incidência de calor que as voltadas para o Sul, com $98 \%$ de ocorrência de temperaturas máximas naquelas encostas. As temperaturas mínimas também ocorreram em grande maioria nas encostas Norte $(86 \%)$, o que deve ser atribuído à maior umidade relativa nas de Sul, face ao maior período de deposição de orvalho, que atua como um efeito "tampão" reduzindo as temperaturas extremas (OLIVEIRA et al., 1995).

Em situações de baixa umidade relativa do ar a probabilidade de ocorrência e propagação do fogo é maior, tendo em vista a correlação direta com a secagem do material combustível. O material mais fino, representado pela classe I ou tempo de resposta de uma hora conforme a classificação de Brown (1982), é aquele presente em maior quantidade e na maioria dos ambientes. Em situações críticas de clima esse material chega a perder até $66 \%$ de umidade no intervalo de uma hora, conduzindo a umidade do material combustível abaixo da umidade de extinção.

De acordo com Nunes (2005) isso se deve ao fato da umidade atmosférica ter efeito direto na inflamabilidade dos combustíveis, havendo uma troca constante de umidade entre a atmosfera e os vegetais mortos. O material seco absorve água de uma atmosfera úmida e libera água quando o ar está seco. A quantidade de umidade que o material morto pode absorver do ar e reter depende, basicamente, da umidade relativa do ar. Durante períodos extremamente secos a umidade pode, inclusive, afetar o conteúdo de umidade do material vivo.

Por outro lado, existem variações internas de caráter geomorfológico que individualizam dentro das encostas áreas mais ou menos propícias a ocorrência de incêndios. Estas são segmentos geométricos que se apresentam sob três formas principais: côncava, convexa e retilínea. As formas côncavas se caracterizam como zonas de convergências de fluxo e, consequentemente, de maior concentração de umidade; ao passo que as convexas e retilíneas (em encostas) condicionam a formação de zonas de divergências de água e baixa umidade, sendo, com isso, mais susceptíveis à ocorrência de incêndios (COURA; SOUZA \& FERNANDES, 2009). 
Tal influência é confirmada pelos resultados do estudo (ver Figura 3), que mostram um maior número de ocorrências nas vertentes convexas e retilíneas em relação às côncavas.

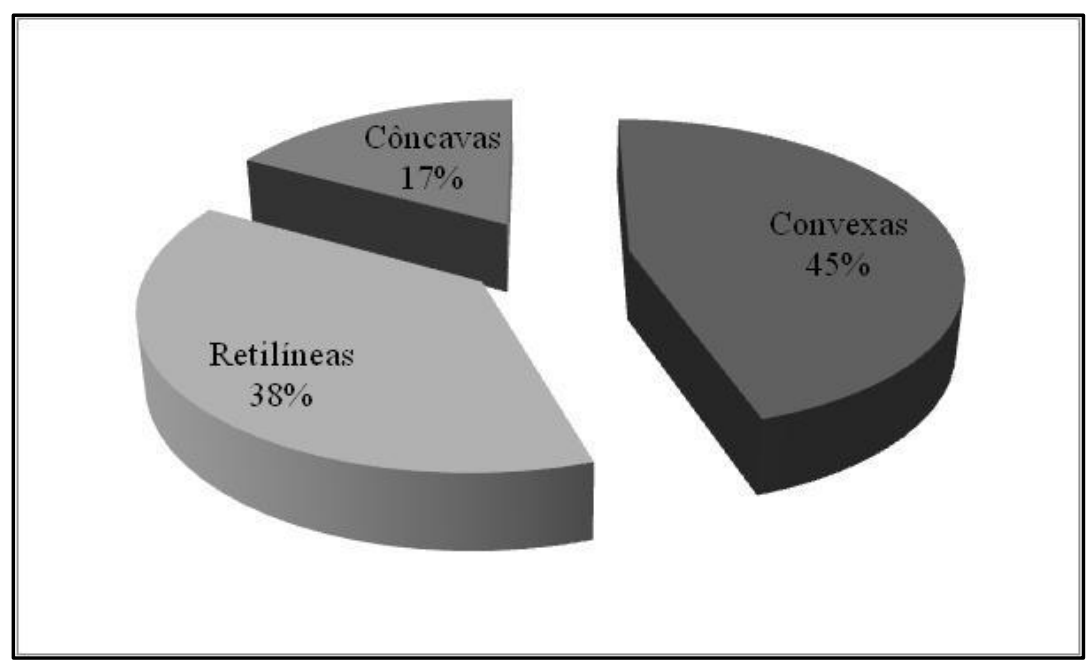

Figura 3: Ocorrências de incêndios de acordo com a forma da vertente.

Com relação à declividade, os dados apontam para os seguintes resultados (Figura 4), a confirmar que quanto maior o declive maior a porcentagem de ocorrências. 


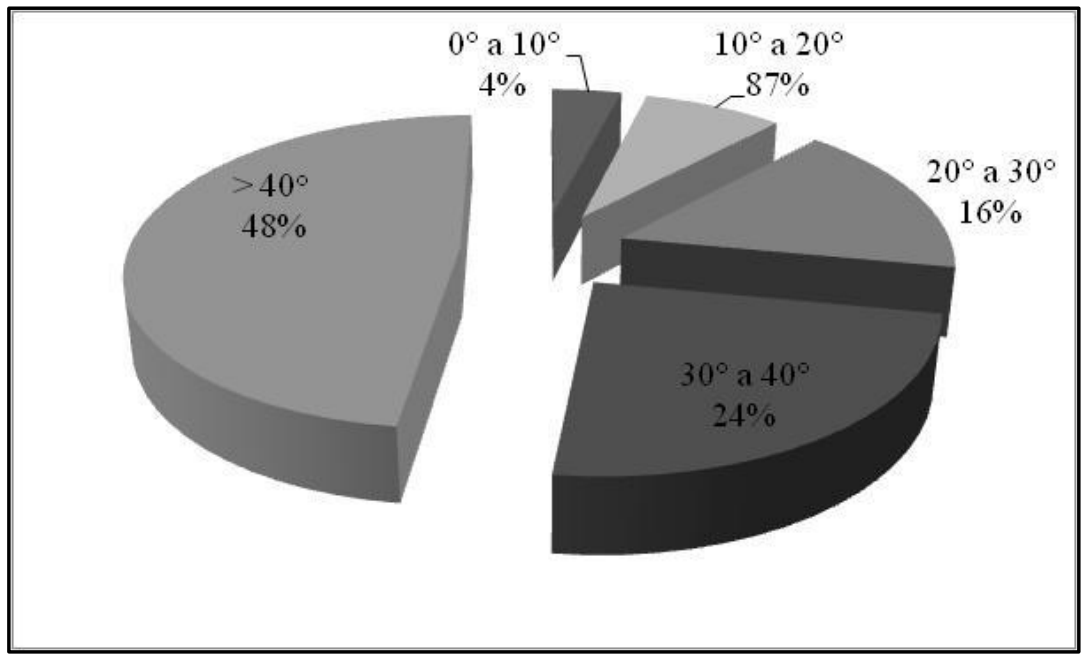

Figura 4: Ocorrências de incêndios de acordo com a declividade.

A influência da declividade pode ser explicada devido à umidade, de acordo com Valeriano (2008). Em encostas mais íngremes percebe-se facilmente que a água da chuva flui com muita rapidez, infiltrando em menor quantidade e tornando o local mais seco.

Além da interferência da inclinação do terreno no fluxo da água, Viegas (2004) explica que a propagação do fogo em locais com alguma declividade tem comportamento distinto daquela que ocorre em áreas sem declividade, em função do efeito de fatores adicionais como a convecção e a radiação. Se existe um mínimo de declividade, a taxa de propagação tende a crescer e será tanto maior quanto maiores forem as transformações microclimáticas na zona de combustão. Esse fato também é confirmado por Ribeiro et al. (2008), quando afirmam que a intensidade do fogo nas áreas de aclive é maior devido ao superaquecimento do material combustível acima da frente da linha de fogo, pela maior proximidade das chamas se compararmos aos terrenos planos. Por outro lado, o vento tende a ajudar tanto na secagem do material combustível quanto na propagação dos incêndios.

De acordo com Torres et al. (2011), o vento é um dos principais fatores que influenciam a taxa de combustão e dispersão do fogo, uma vez que, além de afetar o índice de suprimento de oxigênio durante a queima, a secagem do combustível é acelerada pela remoção da camada de ar em contato com sua superfície e provoca a inclinação das chamas, aproximando-as do material ainda não queimado e acelerando a fase do pré-aquecimento. 
Para os autores, se existe uma declividade e a presença de vento a taxa de propagação tende a crescer.

Os dados da Tabela 1, a seguir, mostram a correlação entre a direção do vento e as ocorrências de incêndios. Vertentes a barlavento dos ventos diários preferenciais apresentam maiores ocorrências de incêndios. Quando a direção preferencial do vento é Norte, há uma predominância de incêndios na vertente exposta ao vento de mesma direção em $71 \%$ dos casos. Quando a direção do vento é Noroeste, $87 \%$ das ocorrências localizam-se nas vertentes voltadas para Norte e Oeste; quando a direção é Nordeste, ocorrem em maior número nas vertentes Norte e Leste, que representam $81 \%$ dos seus incêndios; já no vento de direção Oeste, $77 \%$ das ocorrências se dão na vertente voltada para Oeste; a direção preferencial do vento quando é Leste, favorece as ocorrências nas vertentes Norte e Leste. A influência pode ser mais bem observada quando os ventos têm direção predominante no quadrante Sul (SW, S e SE), onde há uma superioridade de ocorrências na vertente Sul, contrariando o predomínio daquelas que se dão em vertentes de outras orientações. Quando a situação é de calmaria $(\mathrm{C})$, sem ocorrência de ventos, ela se normaliza em relação à ordem observada na Figura 2, com maiores ocorrências na vertente Norte, seguida, respectivamente, pelas vertentes de exposição Oeste, Leste e Sul.

\begin{tabular}{|c|c|c|c|c|c|c|c|c|c|}
\hline \multirow{2}{*}{$\begin{array}{c}\text { Vertente da } \\
\text { Ocorrência }\end{array}$} & \multicolumn{10}{|c|}{ Direção do vento } \\
\cline { 2 - 10 } & $\mathrm{N}$ & $\mathrm{NW}$ & $\mathrm{NE}$ & $\mathrm{W}$ & $\mathrm{E}$ & $\mathrm{SW}$ & $\mathrm{SE}$ & $\mathrm{S}$ & $\mathrm{C}$ \\
\hline Norte (N) & $71 \%$ & $44 \%$ & $54 \%$ & $23 \%$ & $40 \%$ & $22 \%$ & $28 \%$ & $33 \%$ & $65 \%$ \\
\hline Oeste (W) & $15 \%$ & $43 \%$ & $15 \%$ & $77 \%$ & $25 \%$ & $41 \%$ & $12 \%$ & $23 \%$ & $26 \%$ \\
\hline Leste (E) & $10 \%$ & $8 \%$ & $27 \%$ & $0 \%$ & $29 \%$ & $9 \%$ & $29 \%$ & $8 \%$ & $6 \%$ \\
\hline Sul (S) & $4 \%$ & $5 \%$ & $4 \%$ & $0 \%$ & $6 \%$ & $28 \%$ & $31 \%$ & $36 \%$ & $3 \%$ \\
\hline $\begin{array}{l}\% \text { de dias com } \\
\text { vento } \\
\text { predominante }\end{array}$ & $20 \%$ & $11 \%$ & $19 \%$ & $1 \%$ & $11 \%$ & $5 \%$ & $15 \%$ & $14 \%$ & $4 \%$ \\
\hline
\end{tabular}

Tabela1: Percentual de ocorrências de acordo com o local do fogo e com a direção do vento.

Resumindo, quando a direção do vento é a mesma da orientação da encosta, tem-se o chamado "vento morro acima". Nessa situação o vento acelera a propagação do fogo, visto que o mesmo tende a elevar as chamas das partes inferiores para as superiores, ainda não queimadas. 
Torres (2008) produziu um mapa relacionando o número de ocorrências de incêndios em vegetação com a área (em hectare) de cada bairro de Juiz de Fora (ver Figura 5). Nesse estudo, também foi determinado que a maior parte das ocorrências situou-se na face Norte de encostas convexas com declividade superior a $40^{\circ}$, a barlavento dos ventos predominantes.

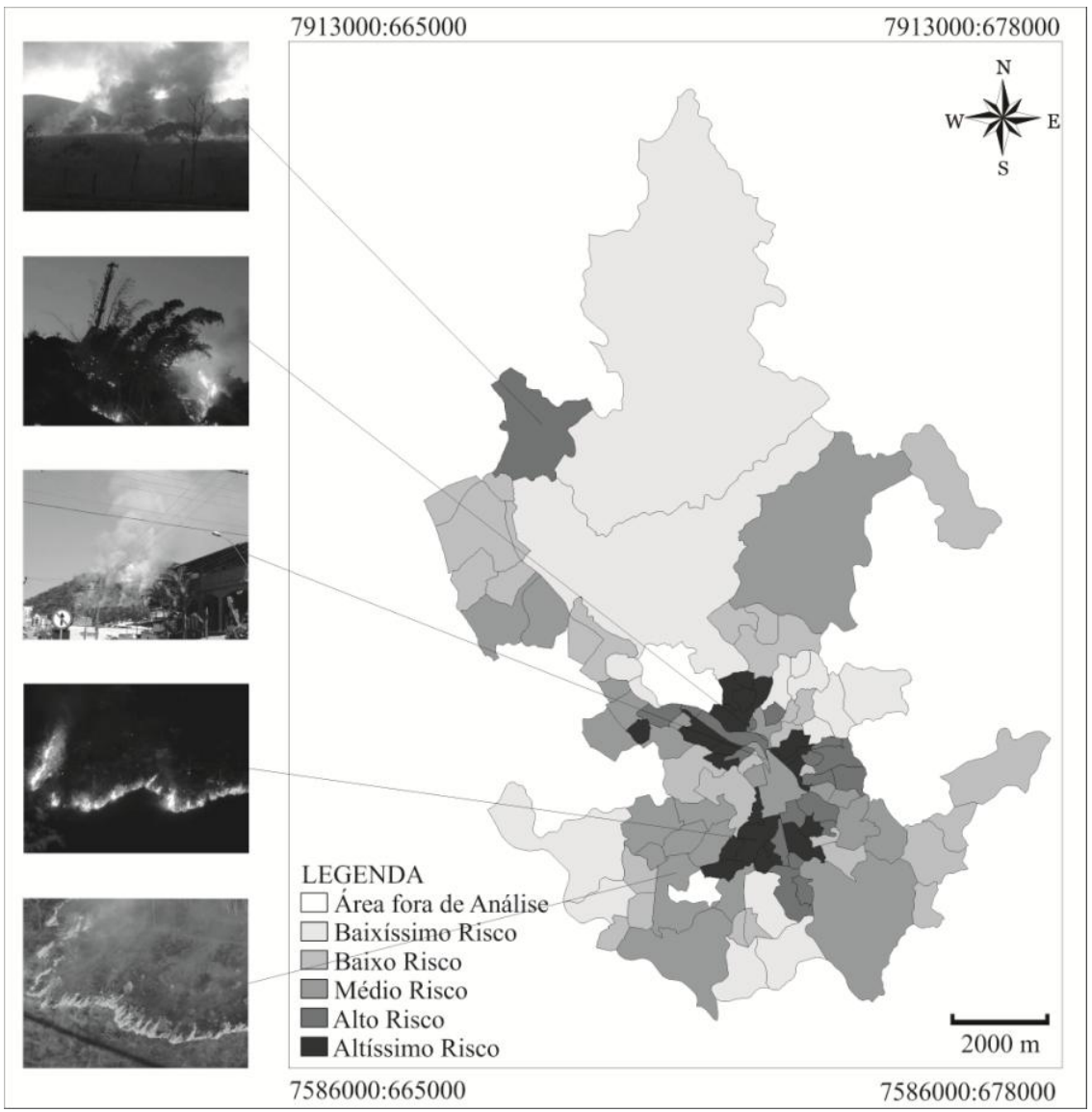

Figura 5: Risco de incêndios em vegetação na área urbana de Juiz de Fora (MG). Fonte: Torres (2008). 


\section{Conclusões}

De acordo com os resultados, concluiu-se que:

- a exposição das vertentes em relação ao Sol tem uma correlação direta com as ocorrências de incêndios;

- as vertentes orientadas para o Norte apresentam maiores índices de ocorrências, visto que a mesma recebe maior quantidade de energia solar durante o ano;

- as vertentes orientadas para o Oeste ficam em segundo lugar na quantidade de ocorrências apresentadas, o que pode ser explicado pelo horário no qual as mesmas recebem maior radiação solar, que coincide com aquele de menor umidade relativa;

- as vertentes a barlavento dos ventos diários preferenciais são mais suscetíveis às ocorrências;

- as vertentes que favorecem a dispersão da água tendem a apresentar mais ocorrências;

- quanto maior o declive, maior o número de eventos;

- estratégias de prevenção a incêndios devem levar em conta as influências do relevo e dos ventos predominantes, através de trabalhos nas áreas mais propícias ao evento. Também as ações de combate devem levar em conta tais informações, diminuindo os custos e riscos das operações.

\section{Bibliografia}

BATISTA, A. C. (2000) Mapas de risco: uma alternativa para o planejamento de controle de incêndios florestais. Floresta, Curitiba, v. 30, $\mathrm{n}^{\mathrm{o}}$ 1/2. pp. 45-54. BROWN, J. K.; OBERHEU, R. D.; JOHNSTON, C. M. (1982) Handbook for inventorying surface fuel and biomass in the Interior West. Ogden: Intermountain Forest and Range Experiment Station.

COURA, P. H. F.; SOUSA, G. M.; FERNANDES, M. C. (2009) Mapeamento geoecológico da susceptibilidade à ocorrência de incêndios no Maciço da Pedra Branca, município do Rio de Janeiro. Anuário do Instituto de Geociências UFRJ, v. 32, n' 2. Rio de Janeiro. pp. 14-25.

HUGGET, R. J. (1995) Geoecology: an evaluation approach. Londres: Editora London.

INSTITUTO BRASILEIRO DE GEOGRAFIA E ESTATÍSTICA. (2010) Censo Demográfico 2010. Rio de Janeiro: IBGE.

NUNES, J. R. S. (2005) FMA + - Um novo índice de perigo de incêndios 
florestais para o Estado do Paraná - Brasil. 150 f. Tese (Doutorado em Engenharia Florestal) - Setor de Ciências Agrárias, Universidade Federal do Paraná. Curitiba.

OLIVEIRA, R. R. et al. (1995) Significado ecológico da orientação de encostas no Maciço da Tijuca. Oecologia Brasiliensis, Rio de Janeiro, nº 1 . pp. 523-541. PREFEITURA DE JUIZ DE FORA. (1996) Plano Diretor de Juiz de Fora. Juiz de Fora: Concorde.

RIBEIRO, L. et al. (2008) Zoneamento de riscos de incêndios florestais para a fazenda experimental do Canguiri, Pinhais (PR). Floresta, v. 38, $\mathrm{n}^{\mathrm{o}} 3$. Curitiba. pp. 561-572.

SANTOS, J. F.; SOARES, R. V.; BATISTA, A. C. (2006) Evolução do perfil dos incêndios florestais em áreas protegidas no Brasil, de 1993 a 2002. Floresta, v. 36, no 1. Curitiba. pp. 93-100.

TORRES, F. T. P. (2008) Análise da ocorrência de incêndios em vegetação da área urbana de Juiz de Fora, MG. 65 f. Dissertação (Mestrado em Ciência Florestal) - Departamento de Engenharia Florestal, Universidade Federal de Viçosa. Viçosa.

TORRES, F. T. P. et al. (2011) Correlações entre os elementos meteorológicos e as ocorrências de incêndios florestais na área urbana de Juiz de Fora, MG. Revista Árvore, v. 35, no 1. Viçosa. pp. 143-150

TORRES, F. T. P.; MACHADO, P. J. de O. (2011) Introdução à Climatologia. São Paulo: Cengage Learning.

VALERIANO, M. M. (2008) Dados topográficos. In: FLORENZANO, T. G. Geomorfologia: conceitos e tecnologias atuais. São Paulo: Oficina de Textos. VIEGAS, D. X. (2004) Cercados pelo fogo. Coimbra: Editorial Minerva.

VOSGERAU, J. L. et al. (2006) Avaliação dos registros de incêndios florestais no Estado do Paraná no período de 1991 a 2001. Floresta, v. 36, nº 1 . Curitiba. pp. 23-32. 